\title{
Vaccinate Early and Vaccinate Broadly: On the health and Economic Effects of COVID-19 Vaccines
}

\author{
Pragyan Deb \\ IMF \\ Davide Furceri \\ IMF \\ Jonathan Ostry \\ IMF \\ Nour Tawk \\ IMF
}

Michael Ganslmeier ( $\square$ michael.gansImeier@spi.ox.ac.uk )

University of Oxford https://orcid.org/0000-0001-6205-4061

\section{Physical Sciences - Article}

Keywords: COVID-19 vaccination campaigns, economic effects, COVID-19 vaccine

Posted Date: May 26th, 2021

DOI: https://doi.org/10.21203/rs.3.rs-525515/v1

License: (9) This work is licensed under a Creative Commons Attribution 4.0 International License.

Read Full License 


\section{Abstract}

Recent progress in COVID-19 vaccination campaigns has provided real hope for people around the world to successfully end the pandemic, decrease fatality rates and lift social distancing rules for timely economic recovery. Even though several RCT and single-country case studies have shown the high efficacy of the developed vaccines, little is known about how vaccination will result in lower cases and higher economic activity at the macro level. Quantifying the speed of these effects using observational data is of great relevance for policymakers as they grapple with decisions on vaccine distribution and equity, costly containment and social distancing measures, healthcare planning and expenditures, and macroeconomic policy support. With this article, we aim to contribute to the pandemic literature by measuring the effect of vaccination rates on new cases and macroeconomic activity indicators using daily real-world observational data from 314 regions/states in 17 countries. Our results show that: (i) vaccination has a delayed containment effect which increases over time; (ii) the effects on changes in economic activity are transitory after large initial rises-that is, vaccination has permanent level effects; and (iii) the effect of the second vaccine dose is only present for new cases while being insignificant for economic activity.

\section{Introduction}

Countries worldwide have begun vaccinating their populations with COVID-19 vaccines, but progress has been slow and uneven (Figure A1). While it is understood that vaccinating a large proportion of the population is ultimately the way out of the pandemic and the economic crisis it has brought about, the impact of vaccine rollouts on health and economic outcomes remains an open question using real-world macro-level data. In general, vaccination affects the spread of coronavirus through two distinct channels. On the one hand, vaccinated individuals get infected and transmit the disease with a lower probability. On the other hand, a sufficiently high vaccination rate induces additional virus containment through herd immunity.

Beyond the public health consequences, infectious diseases such as COVID-19 hamper economic activities in different ways. For instance, previous research has pointed out the distorting effect of strict social distancing rules on economic activity $5,6,7,8$. At the same time, fear of future income and revenue losses among households and firms limits consumption and investments, amongst other mechanisms. Vaccination, in contrast, counteracts these damaging forces the virus brings to the economy by enabling the lifting of lockdown rules and reducing the uncertainty in economic and health prospects.

In this paper, we aim to quantify how and when the effect of vaccination materializes in incidence levels and high-frequency economic activity indicators. Our results suggest that vaccine deployment has large payoffs for both health and economic outcomes even at low levels of vaccination rates. Namely, the effect on new cases is delayed and it increases over time, which is in line with previous epidemiological studies. In contrast to the lagged effect of vaccination, economic activity indicators respond immediately, and the effect becomes smaller over time. In other words, vaccine deployment has transitory effects on 
changes in economic activity but persistent effects on its level. Both the public health and economic effects are substantial and sizeable: a 10-percentage point increase in the share of the population with at least one vaccine dose reduces daily new cases per capita ( 21 days after) by 0.1 percentage point-about 0.3 standard deviation in the new cases per capita. Similarly, the daily change in the number of night-time lights per capita increases by 1 percentage point-about 0.9 standard deviation in the daily change of night-time lights per capita. Our estimates show notable robustness towards model uncertainty and endogeneity concerns.

\section{Methods}

We examine the macro effect of vaccination on new cases and economic activity by using a unique panel dataset consisting of vaccinations, incidences and high-frequency economic indicators covering 314 states/regions in 17 countries for the period between December 21, 2020 until February 28, 2021 at a daily frequency. While the number of new cases per capita and mobile-phone based mobility indicators are widely used measures in the pandemic literature $9,10,11,12,13$, we resort to two additional kinds of highfrequency indicators that aim to capture economic activity $14,15,16,17,18,19$. Specifically, we use daily nighttime-lights and emissions data (aerosol optical depth 550) from the NASA and Copernicus satellite programs, respectively. The high geographical and temporal granularity of these indicators enables us to properly match these economic performance proxies to the relevant public health indicators. In addition, testing the vaccination impact on a range of different economic indicators enables to draw conclusions for different forms of economic activities.

The main strength of our statistical analysis comes with its regional granularity since it enables us to address endogeneity and simultaneity concerns. On one hand, the data structure allows us to address omitted variable bias by controlling for unobserved heterogeneity across regions (e.g., cultural factors that can affect differences in vaccine hesitancy) as well as time-varying factors at the country level affecting incidence levels and economic performance (e.g. imposition of lockdown measures, mask requirements and other factors affecting social distancing). On the other hand, the dataset enables us to apply a quasi-experimental research design using instrumental variables by exploit regional variation in vaccination rollout within countries through measures the capture the quality of the local public health infrastructure (e.g. hospitals per capita). Finally, we explore exogenous changes in vaccination determined by exogenous variations in the number of vaccine procurement and regional-specific factors related to vaccine rollout such as the number of hospital per capita. This quasi-experimental research design allows us to draw causal conclusions.

\section{Results}

\section{The effect of vaccination on incidence levels is delayed but increases with time, while the effects on economic activity are immediate.}


Figure 1 suggests that vaccine deployment has a lagged but large effect on the number of new COVID-19 cases that increases over time. The effect size on new cases after 21 days is already substantial (Table 1): a 10 percent increase in the share of population with one vaccine shot-that is, moving from a region which has started vaccination and is at $25^{\text {th }}$ percentile distribution to a region at the $75^{\text {th }}$ percentile of distribution-reduces the number of daily new COVID-19 cases as share of population by 0.10 percentage point-that is, about 0.33 standard deviation of the new cases population ratio. After 30 days, the same increase in vaccinated people refers to 0.17 percentage point reduction in incidence levels, which refer to about 0.57 of its standard deviation. While the impact of vaccination is expected to diminish once a critical mass of the population is vaccinated, we do not find such non-linear effects in the data so far given generally low levels of vaccinations in most countries during the estimation window.

In contrast, with respect to economic activity estimates, we find that vaccination leads to an immediate jump in nighttime lights, emission levels and mobility changes (Figure 1). In detail, a 10 percent increase in the share of population with one vaccine dose boosts the daily change in the number of: (i) NTLs per capita by about 0.9 standard deviation; (ii) emissions (AOD) per capita by about 1.8 standard deviations; and (iii) and mobility by 0.12 standard deviation after 1 day (Table 1 ). We associated this immediate reflection of greater vaccine coverage in economic activity with increased confidence of immunized individuals, vaccination optimism and perceptions of herd immunity. As Figure 1 illustrates, the large positive effect is indeed declining and becomes less precisely estimated as the delay increases for all economic measures under investigation. Combining this result with the cumulative effect size displayed in Figure A2, we show that vaccination leads to an immediate and persistent increase in economic indicators.

These baseline results on public health and economic outcomes show substantial and statistical robustness to several sensitivity tests. In detail, (i) adding region-specific time trends (Table A1, Figure A3), (ii) repeating the analysis by winsorizing the dependent variables to the 99th percentile of its respective distribution (Table A2, Figure A4), (iii) using the growth rate of new cases as left-hand-side variable, and (iv) re-estimating the baseline after excluding one country at a time (Figure A5) does provide similar estimates and lead to the same conclusion as the baseline results.

\section{The second dose has a large effect new cases but not on economic activity.}

When we extend the analysis to examine the effect of the second vaccine dose by using the 21-day lag as for the share of population with one dose and the 7-day lag as the share of population with full vaccination, our results show that full vaccination has a significant and sizeable impact on the number of new COVID-19 cases per capita (Table 2). In fact, the effect of full vaccination is substantially larger than the effect magnitude of the population share having received at least one dose (Table 2). This result is consistent with the results in the epidemiological literature ${ }^{1,2,3,4}$ on the higher efficacy associated with vaccines, and partly reflects the fact that the variability in the share of population with two doses is considerable smaller. 
For the economic indicators, we consider one-day lag as for the share of population which has received two doses, and control for the share of the population with one dose. By contrast, we do not find statistically significant effects of the second vaccine dose on economic activity (Table 2). This is consistent with our finding that changes in economic activity respond immediately and temporarily to the first vaccine dose-that is, the effect of vaccination on the change in economic activity dissipates by the time of the second vaccine dose. Again, these results point to the importance of optimism and confidence mechanisms.

\section{Vaccination has a causal effect on incidence levels and economic activity}

Even though our empirical approach in the baseline accounts for key omitted variables at the regional and country level, the estimates might still suffer from untreated endogeneity. Thus, using a quasiexperimental research design, we exploit exogenous variation in vaccination rates by using vaccination procurement per country from June until August 2020 and the number of hospitals per capita in each state/region. As in Figure A6-7, countries with high and early procurement are associated with earlier vaccination rollout. Likewise, Figure A8-9 indicates that regions with a high number of hospitals per capita within a country show higher vaccination rates than their counterparts where the number of health provider per habitant is smaller.

Using the interaction between both factors as an instrumental variable for vaccination rates, the results are in line with the baseline estimates by showing the lagged but increasing effect of vaccines on incidence levels and the immediate but transitory impact on economic activity as the delay between vaccination and outcome of interest increases (Figure 2). The very large F-Statistics in the first-stage regression provide confidence in the strength of the research design by making the presence of weak instrument bias very unlikely. Figure A10-13 and Tables A3-7 provide additional details and robustness checks.

\section{Discussion}

In this paper, we have provided empirical evidence using observational data at the macro level to show the impact of COVID-19 vaccinations on coronavirus spread as well as various high-frequency economic activity indicators. In general, our results confirm that the share of vaccinated population has a large impact on incidence levels and economic activity although the speediness of the effects varies. Three aspects are worth highlighting. First, the gains of vaccination materialize in the number of new COVID-19 cases per capita with a delay of 7 days but then increase over time. This finding is in line with RCT studies which document a lagged effect because of delays in immune response and reporting of new cases. Second, the effects on economic activity are transitory by showing substantial increases in the short term while remaining at a plateau as the day since vaccination increases. This finding is in line with increased confidence of immunized individuals immediately after they have received their first dose. Third, the effect of the second dose has only a significant effect on the number of new cases while we do not find associated changes in economic activities. Again, this is in line with a confidence mechanism of 
economic and physical activity through which increases in vaccination coverage materializes already in the very short-term after the first dose.

After more than one year of severe fight against the coronavirus spread, the unprecedented speed of vaccine development comes timely as lockdown fatigue and rising resentments against social distancing regulations gain momentum in many countries around the world. Thus, fast vaccine deployment is the key priority for future public health management in order to limit the health and economic damage the coronavirus has brought about. With the present article, we hope to provide real-world macro-level evidence about the effect of vaccination on pandemic and economic trajectories, which may inform policymakers deciding on existing strategies from lockdown restrictions as vaccination progress is continuing.

\section{Declarations}

Acknowledgements. The views expressed in this paper are those of the authors and do not necessarily represent those of the IMF or its member countries. We thank Bas B. Bakker, Era Dabla-Norris, Allan Dizioli, Chiara Fratto, Carlos Goncalves, Gita Gopinath, Paulo Mauro, Alex Sollaci, Nikola Spatafora as well as participants and discussants from the IMF Surveillance Meeting for their comments and suggestions.

Author contributions. Each author has equally contributed to the paper.

Competing interest declaration. The authors declare no competing financial and non-financial interests.

Additional Information. Correspondence should be addressed to Michael GansImeier (michael.ganslmeier@spi.ox.ac.uk). The datasets generated and analyzed for the empirical analysis of the present research article is available from the corresponding author on request or via Github (@MGansImeier/covid19vaccinationProject):

https://github.com/MGansImeier/covid19vaccinationProject

\section{Main References}

1. Dagan, N., Barda, N., Kepten, E., Miron, O., Perchik, S., Katz, M.A., Hernán, M.A., Lipsitch, M., Reis, B., and Balicer, R.D., 2021. "BNT162b2 mRNA Covid-19 Vaccine in a Nationwide Mass Vaccination Setting”. N Engl J Med, NEJMoa2101765.

2. Polack, F.P., Thomas, S.J., Kitchin, N., Absalon, J., Gurtman, A., et al., 2020. “C4591001 Clinical Trial Group. Safety and Efficacy of the BNT162b2 mRNA Covid-19 Vaccine". N Engl J Med, vol. 383(27), pp. 2603-2615.

3. Logunov, D.Y., Dolzhikova, I.V., Shcheblyakov, D.V., Tukhvatulin, A.I., Zubkova, O.V., et al., 2021. "GamCOVID-Vac Vaccine Trial Group. Safety and efficacy of an rAd26 and rAd5 vector-based heterologous 
prime-boost COVID-19 vaccine: an interim analysis of a randomised controlled phase 3 trial in Russia," Lancet, vol. 397(10275), pp. 671-681.

4. Voysey, M., Clemens, S.A.C., Madhi, S.A., Weckx, L.Y., Folegatti, P.M., et al. 2021. “Oxford COVID Vaccine Trial Group. Safety and efficacy of the ChAdOx1 nCoV-19 vaccine (AZD1222) against SARSCoV-2: an interim analysis of four randomised controlled trials in Brazil, South Africa, and the UK". Lancet, vol. 397(10269), pp. 99-111.

5. Eichenbaum, M., Rebelo, S., and Trabandt, M., 2020. “The Macroeconomics of Epidemics," NBER Working Papers, 26882.

6. Engler P., Poukouam N., Rodriguez, G.D., and Yakadina, I., "The Great Lockdown: International Risk Sharing Through Trade and Policy Coordination," IMF Working Paper, 20/242.

7. Acemoglu, D., Chernozhukov, V., Werning, I., and Whinston, M., 2020. “Optimal Targeted Lockdowns in a Multi-Group SIR Model," NBER Working Papers,

8. Alvarez, F., Argente, D., and Lippi, F., 2020. "A Simple Planning Problem for COVID-19 Lockdown," NBER Working Papers,

9. Fernández-Villaverde, J., and Jones, C., 2020. "Macroeconomic Outcomes and COVID-19: A Progress Report," Brookings Papers on Economic Activity.

10. Sampi, J., and Jooste, C., 2020. “Nowcasting Economic Activity in Times of COVID-19: An Approximation from the Google Community Mobility Report." Policy Research Working Paper;No. 9247.

11. Deb P., Furceri D., Ostry, J., and Tawk, N., 2020. "The Economic Effects of COVID-19 Containment Measures," IMF Working Paper, 20/158.

12. Chen, S., Igan, D., Pierri, N., and Presbitero, A., 2020. "Tracking the Economic Impact of COVID-19 and Mitigation Policies in Europe and the United States," IMF Working Paper, 20/125.

13. Born, B., Dietrich, A., and Muller, G., 2020. “Do Lockdowns Work? A Counterfactual for Sweden," CEPR Discussion Paper, No. DP14744.

14. Bundervoet, T., Maiyo, L., and Sanghi, A., 2015. "Bright Lights, Big Cities: Measuring National and Subnational Economic Growth in Africa from Outer Space, with an Application to Kenya and Rwanda," World Bank Policy Research Working Paper, No. 7461.

15. Henderson, J. V., Storeygard, A., and Weil, D.N., 2011. "A Bright Idea for Measuring Economic Growth," American Economic Review, vol. 101 (3), pp. 194-99.

16. -, 2012. "Measuring economic growth from outer space," American Economic Review, vol. 102(2), pp. 994-1028.

17. Doll, C., Muller, J.P., and Morley, J., 2006. "Mapping regional economic activity from night-time light satellite imagery," Ecological Economics, vol. 57(1), pp. 75-92.

18. Qin, W., Liu, Y., Wang, L., Lin, A., Xia, X., Che, H., Bilal, M., Zhang, M., 2018. “Characteristic and Driving Factors of Aerosol Optical Depth over Mainland China during 1980-2017". Remote Sensing, vol. 10(7), pp. 1064. 
19. Li, Z. and He, X., 2018. "Analyzing the Relationship Between Aerosol Optical Depth and GDP in China by Integrating MODIS and Nighttime Light Data," 7th International Conference on Agrogeoinformatics (Agro-geoinformatics), pp. 1-6.1

20. Streets, D.G., Yan, F., Chin, M., Diehl, T., Mahowald, N., Schultz, M., Wild, M., Wu, Y., and Yu, C., 2009. "Anthropogenic and natural contributions to regional trends in aerosol optical depth, 1980-2006". Geophys. Res., vol. 114, D00D18.

\section{Tables}

Table 1: OLS BASELINE TABLE

\begin{tabular}{lcccc}
\hline & New COVID-19 Cases & $\begin{array}{c}\text { NTL } \\
\text { (change })\end{array}$ & $\begin{array}{c}\text { AOD } \\
\text { (change) }\end{array}$ & $\begin{array}{c}\text { Mobility } \\
\text { (change) }\end{array}$ \\
\cline { 2 - 5 } Vaccinated persons, 1 dose & $\begin{array}{c}\text {-009577*** } \\
\text { (0.002) }\end{array}$ & $\begin{array}{c}0.982963 * * * \\
(0.316)\end{array}$ & $\begin{array}{c}144.329874 * * * \\
(49.897)\end{array}$ & $\begin{array}{c}0.109194 * * * \\
(0.042)\end{array}$ \\
COVID-19 cases (lag) & $-0.602117 * * *$ & -0.702001 & -5.742946 & -0.034895 \\
NTL (lag) & $(0.069)$ & $(0.572)$ & $(6.166)$ & $(0.081)$ \\
& -0.000002 & $-0.029710^{* * *}$ & 0.146945 & -0.000119 \\
AOD (lag) & $(0.000)$ & $(0.008)$ & $(0.100)$ & $(0.000)$ \\
& 0.000001 & -0.000707 & $-0.226594 * * *$ & $0.000071^{* *}$ \\
Mobility (lag) & $(0.000)$ & $(0.001)$ & $(0.061)$ & $(0.000)$ \\
Constant & -0.000715 & 0.040954 & 3.060233 & $-0.545009 * * *$ \\
& $(0.001)$ & $(0.029)$ & $(2.889)$ & $(0.022)$ \\
Observations & $2.835655^{* * *}$ & 1.163777 & -181.590709 & $-10.511556 * * *$ \\
R-squared & $(0.321)$ & $(2.683)$ & $(129.911)$ & $(0.598)$ \\
Vaccination Lags & & & & 21,302 \\
\hline
\end{tabular}

Note: Results reported are based on a sample of 17 countries (314 states) using daily data from December 21, 2020-February 28, 2021. Estimates are based on , where alternatively denotes: the number of new COVID-19 infections as share of population, nighttime lights and AOD per capita and google mobility in region $i$ and country $j$ at day $t$. denotes the share of individuals in the population which have received one vaccine shot. are country-fixed effects, are country-time fixed effects. is a vector of control variables which includes the level of new cases and economic indicators at $t$ - 1 . denotes the lags in the response of the endogenous variable to vaccine. Standard errors clustered at the country-date level in parentheses. $* * *, * *, *$ denote statistical significance at 1 percent, 5 percent and 10 percent, respectively.

\section{Table 2: OLS SECOND SHOT}




\begin{tabular}{|c|c|c|c|c|}
\hline & New COVID-19 Cases & $\begin{array}{c}\text { NTL } \\
\text { (change) }\end{array}$ & $\begin{array}{c}\text { AOD } \\
\text { (change) }\end{array}$ & $\begin{array}{l}\text { Mobility } \\
\text { (change) }\end{array}$ \\
\hline Vaccinated persons, 2 doses & $\begin{array}{c}-0.049951 * * * \\
(0.009)\end{array}$ & $\begin{array}{c}-0.147159 \\
(0.098)\end{array}$ & $\begin{array}{c}-46.973157 * \\
(24.905)\end{array}$ & $\begin{array}{c}-0.156271 \\
(0.097)\end{array}$ \\
\hline Vaccinated persons, 1 dose & $\begin{array}{c}-0.002817^{* *} \\
(0.001)\end{array}$ & $\begin{array}{c}0.358624^{* *} \\
(0.179)\end{array}$ & $\begin{array}{c}156.526323^{* *} \\
(65.146)\end{array}$ & $\begin{array}{c}0.095878 * \\
(0.054)\end{array}$ \\
\hline COVID-19 cases (lag) & $\begin{array}{c}-0.658811 * * * \\
(0.088)\end{array}$ & $\begin{array}{c}-0.043988 \\
(0.105)\end{array}$ & $\begin{array}{c}-15.962639 * \\
(9.446)\end{array}$ & $\begin{array}{c}-0.130926 \\
(0.100)\end{array}$ \\
\hline NTL (lag) & $\begin{array}{c}0.000000 \\
(0.000)\end{array}$ & $\begin{array}{c}-0.214472^{* *} \\
(0.086)\end{array}$ & $\begin{array}{c}10.567962^{* *} \\
(4.174)\end{array}$ & $\begin{array}{c}-0.003992 * \\
(0.002)\end{array}$ \\
\hline AOD (lag) & $\begin{array}{c}-0.000001^{* * *} \\
(0.000)\end{array}$ & $\begin{array}{c}-0.000497 \\
(0.000)\end{array}$ & $\begin{array}{c}-0.428017 * * * \\
(0.107)\end{array}$ & $\begin{array}{c}0.000044 \\
(0.000)\end{array}$ \\
\hline Mobility (lag) & $\begin{array}{c}-0.001308^{* *} \\
(0.001)\end{array}$ & $\begin{array}{c}0.012581 \\
(0.015)\end{array}$ & $\begin{array}{c}-1.423855 \\
(3.347)\end{array}$ & $\begin{array}{c}-0.579447 * * * \\
(0.030)\end{array}$ \\
\hline Constant & $\begin{array}{c}3.192995^{* * *} \\
\quad(0.424)\end{array}$ & $\begin{array}{c}-0.503224 \\
(0.581)\end{array}$ & $\begin{array}{c}-316.752247^{*} \\
(175.752)\end{array}$ & $\begin{array}{c}-10.540112^{* * *} \\
(0.821)\end{array}$ \\
\hline $\begin{array}{l}\text { Observations } \\
\text { R-squared } \\
\text { Vaccination } 2 \text { Lags }\end{array}$ & $\begin{array}{c}12,629 \\
0.370 \\
7 \text { days }\end{array}$ & $\begin{array}{c}13,799 \\
0.742 \\
1 \text { day }\end{array}$ & $\begin{array}{c}13,799 \\
0.297 \\
1 \text { day }\end{array}$ & $\begin{array}{c}13,767 \\
0.776 \\
1 \text { day }\end{array}$ \\
\hline Vaccination 1 Lags & 21 days & 1 day & 1 day & 1 day \\
\hline
\end{tabular}

Note: Results reported are based on a sample of 17 countries (314 states) using daily data from December 21, 2020-February 28, 2021. Estimates are based on , where alternatively denotes: the number of new COVID-19 infections as share of population, nighttime lights and AOD per capita and google mobility in region $i$ and country $j$ at day $t$. denotes the share of individuals in the population which have received one vaccine shot. denotes the share of individuals in the population which have received two vaccine shots. are country-fixed effects, are country-time fixed effects. is a vector of control variables which includes the level of new cases and economic indicators at $t$ - 1 . denotes the lags in the response of the endogenous variable to vaccine. Standard errors clustered at the country-date level in parentheses. ${ }^{* *}, * *, *$ denote statistical significance at 1 percent, 5 percent, and 10 percent, respectively.

\section{Additional Methods}

\section{Data}

We assemble a daily database of economic indicators and COVID-19 incidences covering 314 regions/states in 17 countries between December 21, 2020-February 28, 2021 (Table A8-9). Our main independent variable of interest is the number of vaccine recipients per capita (of at least one dose). The data are collected directly from national governmental websites.

We examine the effect of vaccines on four regional indicators. First, to test the impact of vaccination on coronavirus spread, we use the number of new COVID-19 cases per capita for a given region, extracted from different sources ${ }^{1,2,3}$. To construct the measures of economic activity, we use daily night-time lights (NTL) data from the National Aeronautics and Space Administration ${ }^{4}$ (NASA). The satellite images are taken at 01:30AM local time with a spatial resolution of 500m $\times 500 \mathrm{~m}$. For each region, we divide the 
sum of all daily night-time light pixels by population. The second measure of economic activity is based on Aerosol Optical Depth (AOD) at 550nm, a proxy for emission levels. The data are based on satellite images provided by the Copernicus satellite program of the European Union ${ }^{5}$, which comes with spatial and temporal resolution of $125 \times 125 \mathrm{~km}$ and six-hour intervals, respectively. We aggregate these intradaily records to a daily aerosol emission indicator and divide by population for a given region. Finally, using the Google mobility indicators ${ }^{6}$, we construct a general mobility index which is defined as the average of workplace, transport, and the inverse of residential mobility.

Additional data is sourced for the instrumental variable approach: vaccine procurement data ${ }^{7}$, which records the share of vaccinations ordered on a given date for different vaccination suppliers. For each country, we sum the share of procurement over population over all vaccination suppliers at a specific date. Vaccine procurement is interacted with hospitals per capita from OpenStreetMap Overpass API ${ }^{8}$.

\section{BASELINE ESTIMATION}

In the baseline specification, we regress health (new COVID-19 cases) or economic (changes in nighttime lights, emissions, mobility) outcomes per capita on the vaccine recipients of at least one dose per capita by estimating

$$
\Delta C_{i, j, t}=\alpha+u_{i}+\mu_{j, t}+\beta V_{i, j, t-l}+\theta X_{i, j, t-1}+\varepsilon_{i, j, t}
$$


where $C_{i, j, t}$ alternatively denotes: the number of new COVID-19 cases as share of population, NTLs and AOD per capita and google mobility (defined as the average of workplace, transport and the inverse of residential mobility), in region $i$ and country $j$ at day $t . V_{i, j, t}$ denotes the share of individuals in the population which have received one vaccine dose. $u_{i}$ are country-fixed effects to account for time-invariant region-specific characteristics such as cultural factors that can facilitate (impede) vaccine rollouts. $\mu_{j, t}$ are country-time fixed effects to control for time-varying factors at the country level affecting the evolution of the pandemic and economic activity—such as the imposition of lockdown measures, mask requirements and other factors affecting social distancing. $X$ is a vector of control variables which includes the level of new cases and economic indicators at $t-1 . \ell$ denotes the lags in the response of the endogenous variable to vaccine. For all economic indicators, we consider a one-day lag to reduce the risk of reverse causality. For the number of new cases, we follow the vaccine literature ${ }^{9,10,11}$ and consider in the baseline 21-day lags to allow for delays in reaching virus immunity — we relax this assumption subsequently and examine various lags. For all estimations which has the change in night-time light as dependent variable, we only keep observations where the change in the night-time light per capita series is smaller than 2 to remove outliers that might distort the estimates.

We extend equation (1) to examine the additional effects stemming from the second vaccine dose:

$$
\Delta C_{i, j, t}=\alpha+u_{i}+\mu_{j, t}+\beta V_{i, j, t-l}+\theta V 2_{i, j, t-l}+\theta X_{i, j, t-1}+\varepsilon_{i, j, t}
$$

where $V 2_{i, j, t}$ denotes the share of individuals in the population with two vaccine doses. Equations (1)-(2) are estimated using OLS, with standard errors two-way clustered by country and time.

\section{INSTRUMENTAL VARIABLE (IV) ESTIMATION}

There are two main challenges in identifying the causal effects of vaccines on health and economic indicators. The first is reverse causality. For example, regions with a higher number of new COVID-19 cases or weaker economic activity may act faster to roll out vaccines. The second is joint determinacy: vaccine rollouts could be deployed together with NPIs, which in turn affect the evolution of the pandemic and economic activity. Our baseline specification tries to mitigate these concerns through the use of lagged explanatory variables (for reverse causality), the inclusion of the lagged outcome variables as 
controls, and the extensive set of regional fixed effects (to control for cultural factors that can facilitate (impede) vaccine rollouts) and country-time fixed effects (to control for time-varying factors at the country level affecting the evolution of the pandemic and economic activity-such as the imposition of lockdown measures, mask requirements and other factors affecting social distancing). But there could still be unobserved regional-time varying factors that correlate with vaccine rollout and affect new cases and economic activity.

We thus rely on an Instrumental Variable (IV) approach, which consists of interacting a country-time variable and a constant region-specific variable. The country-time variable we consider is the cumulative number of vaccine deals/procurement from June 1, 2020-August 21, 2020-that is, six months before the administration of vaccines covered in our estimation sample for all countries with four exceptions: for Argentinian, Turkey, and Chile, we consider vaccine procurement three months before; and for India, we consider vaccine procurement 5 month before. Using smaller lags for these four countries provides the strongest instruments in terms of the F-Statistics. We test for the sensitivity of this lag structure through several robustness checks (see below). In general, the identifying assumption is that these deals/procurement decisions are strongly correlated with vaccine rollouts in January-March 2021 and are not correlated with daily shocks affecting the evolution of the pandemic and economic activity-that is, current-year vaccine administration attributable to project approval decisions made last year are unlikely to be correlated with current-year daily shocks to COVID-19 cases and economic activity. The regional term we consider is the (log of the) number of hospitals per capita. The identifying assumption is that regions with a higher number of hospital per capita are able to rollout vaccines faster.

Our empirical framework controls for region and country-time fixed effects. As such, this IV approach follows the same logic of a difference-in-difference estimator ${ }^{12}$. In particular, our IV strategy reads as follows:

$$
C_{i, j, t}=\alpha+u_{i}+\mu_{j, t}+\beta \hat{V}_{i, j, t-l}+\theta X_{i, j, t-1}+\varepsilon_{i, j, t}
$$

with $\quad V_{i, j, t}=\alpha+u_{i}+\mu_{j, t}+\delta Z_{j t-180} * R_{i}+\theta X_{i, j, t-1}+\varepsilon_{i, j, t}$

where $Z_{j t-180}$ denotes the cumulative number of vaccine deals/procurement made in country $j 180$ days before vaccine administration at time $t$, and $R_{i}$ denotes the number of hospitals per capita (in logs). As with all our instrumental variables, our IV estimates denote the local average treatment effects- - that is, the effect explained by exogenous variation in our endogenous variable determined by the instrument. ${ }^{13}$

\section{ROBUSTNESS CHECK FOR INSTRUMENTAL VARIABLE ESTIMATION}


While most of the countries in our sample had started securing vaccine deals already in the first part of 2020, some (such as Chile and Argentina) signed most procurement deals only towards the end of 2020. To check the sensitivity of our results, we repeated the analysis considering deals signed 150 and 120 days before. While the instruments constructed using these combinations are weaker, the second stage results are qualitatively similar to those obtained with the baseline instrument (EX. Table A4-5, Figure A10-11).

Our identifying assumption is that the interaction between vaccine procurement and number of hospitals per capita are not correlated with daily shocks affecting the evolution of the pandemic and economic activity. A potential concern is that past vaccine procurement may be correlated with current NPIs-such as containment measures, mask requirements (Hale et al., 2021), testing capacity (Roser et al, 2020)and these interventions affects current new cases and economic indicators through regionals factors correlated with hospitals per capita. To address this issue, we augment the baseline IV specification by including the interaction between these NPIs and hospitals per capita. The results presented in Ex. Table A6 and Figure $A 12$ show that the IV results remain robust.

Another similar concern is that past vaccine procurement may be correlated with past NPIs and health and economic indicators (new cases, mobility, emissions and NTLs) -that is, that countries that signed vaccine contracts were also able to better control the pandemic, We check the robustness of our results by including in the IV specifications the interaction between the number of hospital per capita and NPIs, health and economic indicators 180 days before-that is, at the time when vaccines were procured. The results presented in Ex. Table A7 and Figure A13 show that the IV results remain robust.

Finally, we considered the number of hospitals per capita as the regional factor affecting ability to administer vaccines. We find that other regional characteristics such as (the log of) the inverse of population and (the log of) the number of doctors per capita contribute to facilitating vaccine rollout at the regional level. While the first stage results are considerably weaker, we find that for the combinations of dependent variable/horizon for which the instrument is strong-that is, the Kleibergen-Paap rk Wald $\mathrm{F}$ statistic exceeds the Stock-Yogo critical value-the IV results obtained using these regional characteristics are broadly similar to those obtained with hospitals per capita.

\section{Data and code availability statement}

The datasets generated and analyzed for the empirical analysis of the present research article is available from the corresponding author on request or via Github (@MGansImeier/covid19vaccinationProject):

https://github.com/MGansImeier/covid19vaccinationProject

\section{Methods References}


1. Microsoft bing COVID-19 tracker. (n.d.). Microsoft Corporation. Retrieved March 19, 2020, from https://www.bing.com/covid.

2. Abbott, S., Sherratt, K., Bevan, J., Gibbs, H., Hellewell, J., Munday, J., et al.,2020. Covidregionaldata: Subnational data for the covid-19 outbreak.

3. Wahltinez, O., et al. 2021. Open COVID-19 Dataset. Available at https://github.com/open-Covid19/data(accessed April 01, 2021).

4. Román, M.O., Wang, Z., Shrestha, R., Yao, T., and Kalb, V., 2019. Black marble user guide version 1.0. NASA: Washington, DC, USA.

5. ECMWF. CAMS Near-real-time. Retrieved April 01, 2021, from https://apps.ecmwf.int/datasets/data/cams-nrealtime/levtype=sfc/

6. Google LLC, Google COVID-19 Community Mobility Reports. Retrieved from: 'https://www.google.com/COVID-19/mobility/' [Online Resource], (2021)

7. Duke Global Health Innovation Center, 2020. Launch and Scale Speedometer. Duke University. Retrieved from: https://launchandscalefaster.org/speedometer-data

8. OpenStreetMAP. Retrieved from: https://wiki.openstreetmap.org/wiki/Overpass_API

9. Dagan, N., Barda, N., Kepten, E., Miron, O., Perchik, S., Katz, M.A., Hernán, M.A., Lipsitch, M., Reis, B., and Balicer, R.D., 2021. "BNT162b2 mRNA Covid-19 Vaccine in a Nationwide Mass Vaccination Setting". N Engl J Med, NEJMoa2101765.

10. Polack, F.P., Thomas, S.J., Kitchin, N., Absalon, J., Gurtman, A., et al., 2020. “C4591001 Clinical Trial Group. Safety and Efficacy of the BNT162b2 mRNA Covid-19 Vaccine”. N Engl J Med, vol. 383(27), pp. 2603-2615.

11. Logunov, D.Y., Dolzhikova, I.V., Shcheblyakov, D.V., Tukhvatulin, A.I., Zubkova, O.V., et al., 2021. "GamCOVID-Vac Vaccine Trial Group. Safety and efficacy of an rAd26 and rAd5 vector-based heterologous prime-boost COVID-19 vaccine: an interim analysis of a randomised controlled phase 3 trial in Russia," Lancet, vol. 397(10275), pp. 671-681.

12. Nunn, N., and Qian, N., 2014. "US food aid and civil conflict," American Economic Review, vol. 104(6), pp. 1630-66.

13. Imbens G.W., Angrist J.D., 1994. "Identification and Estimation of Local Average Treatment Effects". Econometrica, Vol. 62, No. 2. (Mar., 1994), pp. 467-475.

\section{Figures}



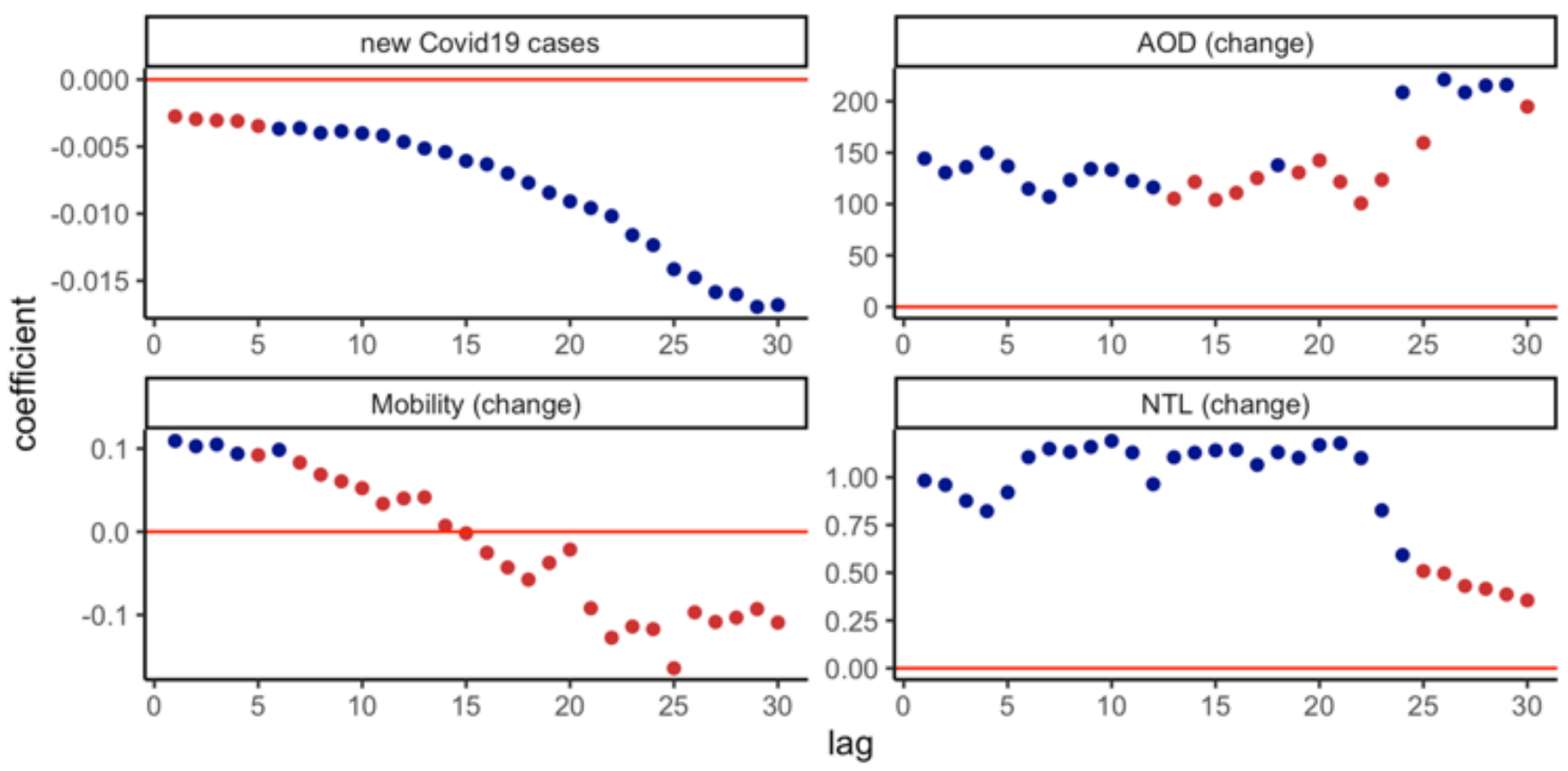

- not significant ( $p$-value $>5 \%$ ) $\quad$ significant ( $p$-value $<5 \%$ )

\section{Figure 1}

OLS LAG PLOT (Please see manuscript for complete figure caption.)
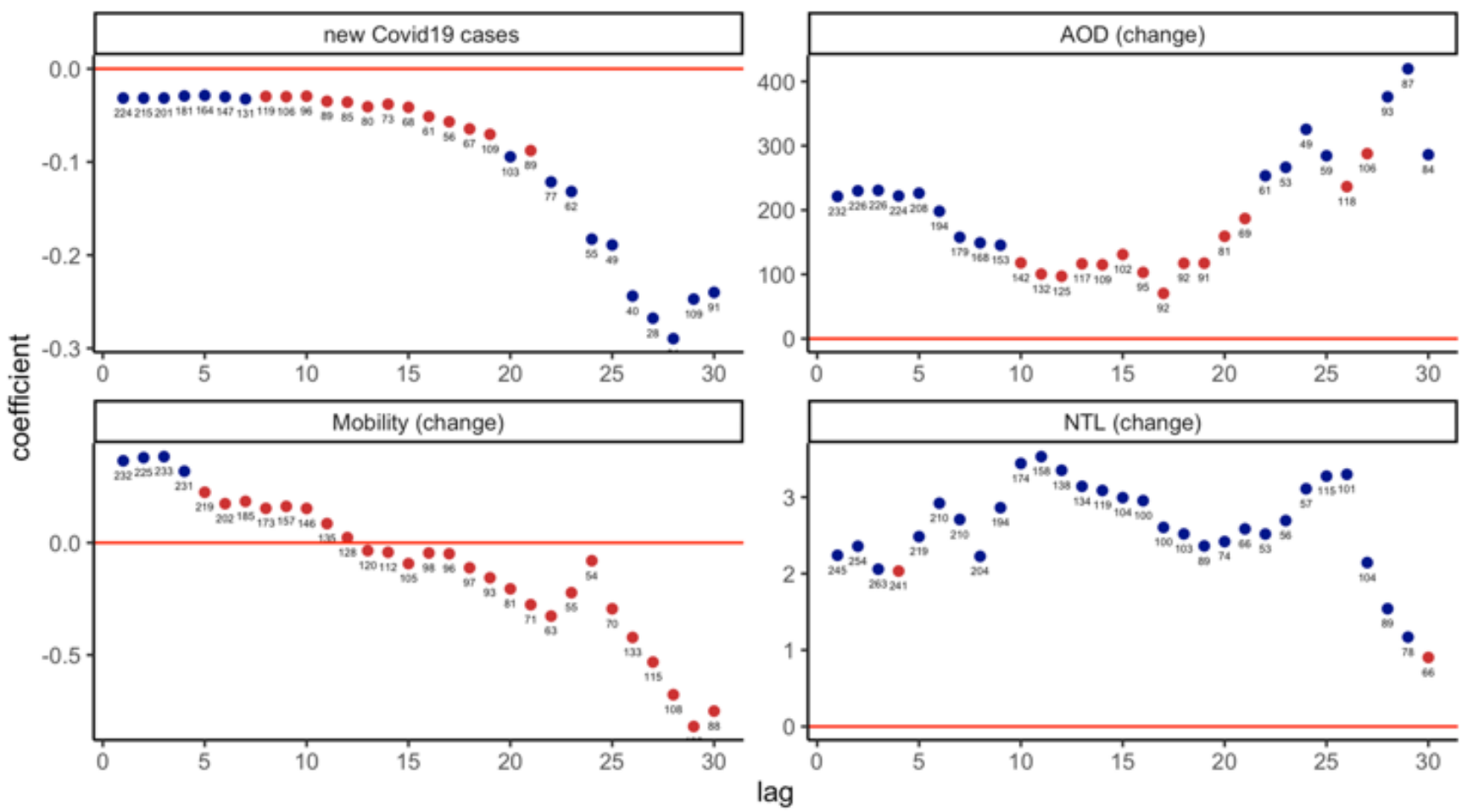

- not significant ( $\mathrm{p}$-value $>5 \%$ )

significant (p-value $<5 \%)$

Figure 2 
IV LAG PLOT (Please see manuscript for complete figure caption.)

\section{Supplementary Files}

This is a list of supplementary files associated with this preprint. Click to download.

- ExtendedDataTablesandFigures.docx 